\title{
Towards a Service-Oriented Energy Market: Current State and Trend
}

\author{
Giuliano Andrea Pagani and Marco Aiello \\ Distributed Systems Group \\ Johann Bernoulli Institute \\ University of Groningen \\ Nijenborgh 9, 9747 AG, The Netherlands \\ \{g.a.pagani,m.aiello\}@rug.nl
}

\begin{abstract}
The energy sector, which has traditionally been an oligarchic closed one, is undergoing major changes at all levels: more and more players are authorized to produce, deal and transport energy, and energy consumers are now in the position to also produce and trade energy. This new trend can be supported by Service-Oriented Architectures (SOAs) at all levels. In this short position paper, we overview the current situation of the energy sector and we indicate challenges for SOA to be addressed for a successful unbundling of the energy arena, thus providing a more efficient infrastructure with both environmental and economic benefits.
\end{abstract}

Keywords: SOAs in practice, Energy, Power Grid.

\section{Introduction}

The energy production and distribution sector was traditionally a strong monopoly with a fixed hierarchy that resembles a client-server architecture: one large provider and infrastructure owner, and millions of end-users. After decades of very little change, in recent years new regulations, technologies and demands from the public are re-shaping the sector. Governments are pushing for the unbundling of the market (e.g., 2] ), renewable energy sources are becoming convenient and available both at the industrial and at the residential scale [14, and environmental concerns about energy production and its side-effects on the climate are becoming a strong focus of public attention. Therefore, the vision is that of an Energy sector where any stakeholder can consume and produce energy (a.k.a. prosumer) while being entirely free to trade it in an open market. This brings a huge number of autonomous actors that need to interact, sign servicelevel agreements, conduct trade and provision energy. The future of the Energy sector might be to become a dynamic and open infrastructure which pervades our lives exactly like the Internet does today.

We argue that looking at the current state and trends of the Energy sector, Service-Oriented Architectures will provide a solid foundation to support the new trend, though to be able to do so a number of new challenges will have to be addressed. Our study is not only based on a literature survey, but also 
personal interaction with the large and medium energy players of the Netherlands (TenneT, Enexis, Essent, Itron, Phase-to-phase, RenQi, among others). This paper is industrial providing vision, requirements, and challenges in relation to SOAs. It is a summary of the extended works [1110 and it is organized as follows. In Section 2 we consider the current situation of the Energy sector. We then provide an overview of technologies used for energy trading in Section 2 Section 3 illustrates the challenges of supporting the future scenario and the relation to SOAs. Concluding remarks are summarized in Section 4 .

\section{The Energy Sector}

The Energy sector is ready for a radical shift driven, on the one hand, by technological innovation with, for example, the introduction of ecological generation facilities (both at a large and micro-scale level) and distributed power sources [8] and, on the other hand, by the political push to break the monopolies and unbundle the market. This is supported, for example, by recent EU directives emphasizing the strategic importance of a Smart Grid approach [56]. But first we consider the organization of this sector. The Power Grid is partitioned (both topologically and organizationally) into three major segments: High, Medium and Low voltage. Energy is mainly produced in large facilities at the High voltage level by a few authorized actors while end users exist mostly at the Medium and Low voltage. The structure is hierarchical. The new directives which promote the unbundling aim at placing more actors at the higher levels to improve efficiency and reduce costs while keeping the same level of service and reliability.

The Energy sector is not only about the physical infrastructure for the production and the control of energy transport, but it is also about the data exchanges that have to take place in order to manage energy billing, trading and the business involved in the creation of added value around energy delivery.

The entire system can be divided in three layers that have different purposes:

- The physical layer is the lowest in the stack and it interacts directly with the electrical apparatus (e.g., transformers, switchgear, relays) that belongs to a distribution substation and power plant control equipment.

- The data layer spans the control data used to supervise and actuate the physical equipment to all the interactions necessary to properly govern the different systems involved in production, transmission and distribution of energy. It enables remote operations on the physical equipment and interaction between the various components of the grid (e.g., sensors and actuators).

- The business layer is formed by information coming from the data layer and is a key element for running the business of electricity. It can be used to measure company performances through key performance indicators, to create new business models and opportunities and to make important forecasts for future trading opportunities and needs.

Stakeholders in the Energy Sector. In the current situation, the typical roles an energy company has in a monopolistic market are: power generation, 
grid management, energy supply, metering and billing. Previously all these roles were held by only one institution, possibly governmental. The current and future trend is to unbundle the market and increase the number of actors at all levels.

What becomes interesting in the future scenario is that there are several companies involved in the same business segment and all need to send and receive essential information to properly operate. Many players for each business category are able to join and contribute to the flow of information. In order to successfully interact with each other a standard, scalable and secure way of exchanging information is required.

A new Grid. An investigation of the Smart Grid concept with all its facets is beyond the scope of this short paper. However it is important to highlight the potential benefits for energy savings and environment a pervasive installation of Smart Grid technology can provide: savings around 20\%. The figure is what the Pacific Northwest National Laboratory has found in a study analysing the energy trends up to 2030 in the U.S.A. 9]. Another study from Electrical Power Research Institute estimates a reduction up to 211 million metric tons of $\mathrm{CO}_{2}$ per year in 2030 thanks to the savings possible through Smart Grid [4].

What is relevant is the implication in terms of necessary modernization, i.e., the increase in the number of actors and system components that communicate with each other from an information infrastructure perspective (e.g., smart meters, home appliances, plug-in hybrid electric vehicles) and interact directly or indirectly with the energy market.

Current systems for energy trading. Consider six major energy markets (US, UK, Japan, Germany, France, and Italy) which all have an operational

Table 1. G6 Countries Information Systems Energy Markets Interaction Summary

\begin{tabular}{|c|c|c|c|c|c|c|c|}
\hline $\begin{array}{l}\text { Market } \\
\text { Manager }\end{array}$ & Land & \begin{tabular}{|l|}
$\#$ \\
Partic- \\
ipants
\end{tabular} & \begin{tabular}{|l|} 
Web \\
Inter- \\
face
\end{tabular} & $\begin{array}{l}\text { Upload } \\
\text { Download }\end{array}$ & $\begin{array}{l}\text { Web } \\
\text { Ser- } \\
\text { vice }\end{array}$ & SOA & Open Solution \\
\hline $\begin{array}{l}\text { GME (http://www. } \\
\text { mercatoelettrico. } \\
\text { org/) }\end{array}$ & ITA & 190 & 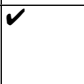 & $\boldsymbol{V}$ XML format & $\checkmark$ & $\checkmark$ & Open \\
\hline $\begin{array}{lrr}\text { ISO New } & \text { Eng- } \\
\text { land } & & \text { (http: } \\
\text { //www } & \text { iso-ne. } & \text { com/ })\end{array}$ & USA & 4 & $V$ & $\begin{array}{l}\text { CSV and XML } \\
\text { format }\end{array}$ & $x$ & $x$ & $\mathrm{~N} / \mathrm{A}$ \\
\hline $\begin{array}{lr}\text { PJM } & \text { Intercon- } \\
\text { nection } & \text { (http: } \\
/ / \text { www.pjm.com) }\end{array}$ & USA & 612 & $V$ & $\checkmark$ XML format & $V$ & $\checkmark$ & $\begin{array}{l}\text { Software tools are } \\
\text { proprietary, but in- } \\
\text { terfaces are open }\end{array}$ \\
\hline $\begin{array}{l}\text { Elexon (http://www. } \\
\text { elexon.co.uk) }\end{array}$ & UK & 226 & $V$ & $\begin{array}{l}\boldsymbol{V} \text { format according } \\
\text { IDD rules }\end{array}$ & $x$ & $x$ & $\begin{array}{l}\text { Open to some ex- } \\
\text { tent }\end{array}$ \\
\hline $\begin{array}{l}\text { European } \quad \text { Energy } \\
\text { Exchange }(\text { http: } \\
\text { //www.eex.com/en/) }\end{array}$ & D & 160 & $V$ & \begin{tabular}{|lrr}
$\boldsymbol{v}$ & CSV & format \\
(for & ComTrader \\
platform) &
\end{tabular} & $x$ & $x$ & $\begin{array}{l}\text { Proprietary Xetra } \\
\text { based software }\end{array}$ \\
\hline $\begin{array}{lr}\text { European } & \text { Power } \\
\text { Exchange } & \text { Spot } \\
\text { (http://www. } & \\
\text { epexspot.com/en/) }\end{array}$ & $\mathrm{F}$ & 80 & $V$ & $\mathrm{~N} / \mathrm{A}$ & $x$ & $x$ & $\begin{array}{l}\text { Proprietary soft- } \\
\text { ware (SAPRI, } \\
\text { Global Vision) }\end{array}$ \\
\hline $\begin{array}{l}\text { Japan Power Ex- } \\
\text { change Spot (http: } \\
\text { //www.jepx.org/) }\end{array}$ & JP & 48 & $\checkmark$ & $\mathrm{N} / \mathrm{A}$ & $\mathrm{N} / \mathrm{A}$ & $\mathrm{N} / \mathrm{A}$ & $\begin{array}{l}\text { Open as far the } \\
\text { small amount of in- } \\
\text { formation suggest }\end{array}$ \\
\hline
\end{tabular}


structure very similar to each other providing the possibility to trade energy with different time granularity (e.g., from hours to minutes) and with different time horizons (e.g., from real-time markets to one year forward contracts). In Table 1, we summarize the findings of a comparative study of these markets (full study in [10]). A number of interesting facts emerge from the comparison: (1) the number of participants involved is low and can change considerably; (2) web interfaces are the only constant, while there is varying IT support for interaction; (3) the solutions are mostly open, though not standardized.

\section{Open Power Grids via Service-Oriented Architectures}

After the legal unbundling of the markets, the appearance of renewable generating facilities at all scale levels, the standardization of the control elements of the Power Grid, and the diffusion of digital/data prone smart meters, all the ingredients seem to be there, but how can these elements provide for a different energy landscape? The challenges that seem to emerge are the following ones.

Interoperation. The number of actors populating the energy market is constantly increasing and their capabilities as well. There is a strong need to have standards for interoperation at all levels (not only the control layer of the grid). Furthermore, standards tend to cover the syntactic part of the interoperation, while the semantics of the message exchange is scarcely addressed.

Scalability. The increase of actors also involves scalability issues. If millions of micro energy producers start trading micro-quantities of energy, there must be an appropriate infrastructure to manage this, possibly real-time, information exchange.

Discovery. If the actors increase and more entities can take on the same role, one may think of discovering services on the fly. The idea of signing an yearly contract for a home, may be too limiting and one may want to switch energy supplier on a much shorter time frame. Furthermore, if anybody can be a supplier, then one may want to find a provider in the instant it is needed.

Mobility. In the future grid energy consumers, and also producers, may be mobile on the grid. Cars will be electric, but may also have energy producing and storing facilities (e.g., a solar cell roof, fuel cells powered engine). The mobile elements need to interact with the Power Grid in a transparent way.

Pervasiveness. Computation needs to be available everywhere on the Grid, if all actors need to participate into the Energy SOA.

Resilience to failure and trust. The electrical Power Grid is a critical infrastructure. A key performance indicator of the current energy distributors is the down time that should not exceed the few hours per year. When moving to an open Smart Grid the delivery of energy must not decrease in quality. This requires having a trust mechanism among the various players and an overall secure infrastructure. It may also require having reliable forecasting of generation and use. 
Service Integration and composition. The physical layer, the data layer and the business layer will have to interact more closely as any node who produces energy needs to control it and guide it into the grid, get paid for it, or make the generation part of a larger business process relying on the energy (e.g., one could drive an electric car while lodging at a motel, plug it into the grid and use the car generated electricity to pay part of the bill [14).

Topology. The current infrastructure is strongly hierarchical. Very few large energy producers and backbone owners, some actors in the middle segment, and many end users with limited flexibility. But the new vision of the open grid demands for a flat peer-to-peer network in which all actors are producers and consumers of energy, data and services.

Real-time. Energy related operation such as control, actuation, distribution and trading have very strict time-dependant constraints to satisfy. All the players in the next generation grid must interact following real-time commitments to provide and receive an energy service with the proper quality.

Interestingly, these challenges are typically best addressed by a Service-Oriented Architecture (e.g., [12]). Let's consider them one by one.

Interoperation. Web services are a technology to build service oriented architecture and address the problem of interoperation being standardized XML protocols to describe messages, remote operations and coordination among loosely coupled entities, e.g., [7.

Scalability. The basic SOA pattern: publish-find-bind allows to decouple service consumers from producers and to substitute, even at run-time, one component for another one. The communication, most often asynchronous, provides all the ingredients for a highly scalable infrastructure. Examples of which have already appeared in the area of eBusiness.

Discovery. Discovery is one of the basic ingredients of a SOA. It needs to support the publish and find operations and is usually based on registries, but can also be realized with flooding models.

Mobility. An SOA supports actor loosely coupling and behaviour based binding, therefore the mobility of the elements is easily supported, e.g., [1].

Pervasiveness. In the SOA paradigm the smart meter is basically a service provider and a service consumer at the same time. It invokes other services to interact on the market and also provide services both to other market participants interested in energy purchase and to intelligent home appliances that require energy at a certain time.

Resilience to failure and trust. Protocols exist to enable a web service based SOA with trust, privacy and security support. This can provide the basic for a secure infrastructure. Reliability and physical security will also have to be pursued with appropriate energy technology which is beyond the SOA.

Service Integration and composition. Service integration and composition is the key added value of an SOA and many examples exist on methodologies to support this, e.g., 3.

Topology. SOAs support any kind of topology. The hierarchical client-server one is less common, but can be realized; P2P is the most common. 
Real-time. Solutions are available to introduce enhancements to SOA paradigm in order to provide an appropriate quality of service and satisfy real-time constraints, e.g., [13].

\section{Concluding Remarks}

The Energy sector is undergoing important changes that are bringing many more players onto the Energy scene. With decentralized small generators everybody can become an energy producer and therefore interact with the market to sell and buy energy. This vision is going to be achieved with technologies that are in development following the Smart Grid vision. More flexible and scalable software solutions based on SOA have already been proposed for control purposes of energy systems belonging to the Smart Grid. The next step is to provide a general infrastructure to support standardized, real-time, open energy trading.

\section{Acknowledgements}

Pagani is supported by the Ubbo Emmius Fellowship 2009 provided by the University of Groningen. The work is supported by the EU FP7 Project GreenerBuildings, contract no. 258888.

\section{References}

1. Aiello, M., Dustdar, S.: A domotic infrastructure based on the web service stack. Pervasive and Mobile Computing 4(4), 506-525 (2008)

2. Cossent, R., Gómez, T., Frías, P.: Towards a future with large penetration of distributed generation: Is the current regulation of electricity distribution ready? regulatory recommendations under a european perspective. Energy Policy 37(3), 1145-1155 (2009)

3. Dustdar, S., Schreiner, W.: A survey on web services composition. Int. J. Web Grid Serv. 1(1), 1-30 (2005)

4. EPRI: The green grid: Energy savings and carbon emissions reductions enabled by a smart grid. Tech. rep., EPRI (2008)

5. EU: Vision and Strategy for Europe's Electricity Networks of the Future, European Technology Platform SmartGrids. Tech. Rep. EUR 22040, EU (2006)

6. EU: Towards smart power networks, lessons learned from european research fp5 projects. Tech. Rep. EUR 21970, European Commission (2007)

7. Leymann, F., Roller, D., Schmidt, M.T.: Web services and business process management. IBM Systems Journal 41(2), 198-211 (2002)

8. Lovins, A.B., Datta, E.K., Feiler, T., Rabago, K.R., Swisher, J.N., Lehmann, A., Wicker, K.: Small is profitable: the hidden economic benefits of making electrical resources the right size. Rocky Mountain Institute (2002)

9. Pacific Northwest National Laboratory: The smart grid: An estimation of the energy and $\mathrm{CO}_{2}$ benefits. Tech. rep., Pacific Northwest National Laboratory (2010) 
10. Pagani, G.A., Aiello, M.: Energy market trading systems in g6 countries. Tech. Rep. JBI preprint 2010-6-01, JBI, University of Groningen (2010)

11. Pagani, G.A., Aiello, M.: Towards a service-oriented energy market: Current state and trend. Tech. Rep. JBI preprint 2010-6-02, JBI, University of Groningen (2010)

12. Papazoglou, M.P., Georgakopoulos, D.: Service-oriented computing. Commun. ACM 46(10), 24-28 (2003)

13. Tsai, W., Lee, Y.h., Cao, Z., Chen, Y., Xiao, B.: RTSOA: Real-Time ServiceOriented Architecture. In: 2006 Second IEEE Int. Sym. Service-Oriented System Engineering (SOSE 2006), pp. 49-56 (October 2006)

14. Vaitheeswaran, V.: Power to the People. Earthscan (2005) 